\title{
GESTÃO E ORIENTAÇÃO PARA OS CLIENTES: UM ESTUDO EM RESTAURANTES POR QUILO UTILIZANDO O MODELO DE ANÁLISE DE IMPORTÂNCIA E DESEMPENHO (IPA)
}

\author{
Sérgio Luiz do Amaral Moretti \\ Doutor em Ciências Sociais pela Pontifícia Universidade Católica de São Paulo - PUC \\ Professor do Programa Mestrado e Doutorado em Administração da Universidade Nove de Julho - \\ PPGA/UNINOVE \\ E-mail: sergiomoretti@uol.com.br (Brasil)
}

\section{José Edson Moysés Filho}

Doutorando em Administração da Universidade Nove de Julho - UNINOVE

E-mail: zezemoyses@laffriolee.com.br (Brasil)

\section{Renato Ferreira Pimenta \\ Doutorando em Administração da Universidade Nove de Julho - UNINOVE \\ Professor da Universidade Nove de Julho - UNINOVE \\ E-mail: pimentamkt@gmail.com (Brasil)}

\section{RESUMO}

Os estudos sobre gestão de pequenas e médias empresas (PMEs) sob a ótica da orientação para o mercado (OPM) têm sido raros no Brasil. Este artigo tem como objetivo averiguar quais atividades de marketing, concebidas sob os princípios da OPM, são adotadas por uma amostra de restaurantes por quilo (PMEs) com mais de 10 anos de existência na cidade de São Paulo, na qual foi aplicado o modelo de análise de importância (IPA). Os resultados parecem indicar que há uma dinâmica gerada pelos colaboradores internos que identificam desejos e preferência dos clientes e os transformam em serviços.

Palavras-chave: Orientação para o mercado (OPM); Pequenas e médias empresas (PMEs); Modelo de análise de importância e desempenho (IPA). 


\section{INTRODUÇÃO}

Recentemente, diversas pesquisas relataram que uma eficiente gestão de marketing focada na orientação para o mercado (OPM) (Rojas-Mendez, Kara, \& Spillan, 2006; Tavares, Ferreira, \& Lima, 2009; Yang, 2008) pode conduzir pequenas e médias empresas (PMEs) a melhores desempenhos, traduzidos por indicadores de gestão econômicos ou financeiros (Barker \& Sinkula, 2009; Hourd \& Williams, 2008; Sampaio, Perin, \& Ferreira, 2008; Teles, 2007; Verhees \& Meulenberg, 2004). Por outro lado, a ausência de uma clara orientação para o mercado pode traduzir-se em desempenho negativo para PMEs (Pereira, Lucas, \& Minciotti, 2008).

No início da década de 1990, estudos sobre a OPM ganharam robustez no meio acadêmico. As pesquisas de Day (1994), Deshpandé, Farley e Webster (1993), Jaworski e Kohli (1993) e Narver e Slater (1990) buscavam descrever as características das empresas orientadas para o mercado apontando uma provável relação entre desempenho positivo nos negócios e OPM. Entretanto, apesar do vigor e da popularidade destas ideias, não havia uma consolidação clara e uniforme sobre o tema, ainda que a análise fosse realizada sob diferentes perspectivas, como o enfoque cognitivo a partir da cultura organizacional e da tomada de decisões (Shapiro, 1988) ou relacionada a amplos processos organizacionais com a participação efetiva de seus recursos humanos (Ruekert, 1992).

Uma linha dominante nas estratégias de OPM é bastante influenciada pela proposta de relacionamento com os clientes, sobretudo pelo impacto que pode causar no estabelecimento de relações consistentes desses com a organização. Baker, Simpson e Siguaw (1999) e Siguaw, Simpson e Baker (1998) relatam evidências de fortalecimento nas relações entre clientes e fornecedores quando existe uma simetria no grau de OPM entre ambos. Da mesma forma, pesquisas (Cannon \& Homburg, 2001) mostram que há uma forte relação entre o desempenho das empresas e as atividades colaborativas entre fornecedores e clientes para encontrar melhores soluções para os problemas dos clientes (Moretti, Moysés, \& Pereira, 2010; Souza \& Mello, 2007).

Este estudo pretende averiguar a relação entre OPM e PME em uma amostra de restaurantes por quilo na cidade de São Paulo. A questão que orienta a pesquisa é descobrir quais são as atividades que restaurantes por quilo, com mais de 10 anos de existência na cidade de São Paulo, desenvolvem a fim de promoverem um desempenho superior no ambiente em que atuam. O artigo está organizado da seguinte forma: primeiramente, o referencial teórico extraído da literatura específica sobre o tema estudado, os procedimentos metodológicos adotados para a pesquisa, uma análise e a discussão dos resultados e as considerações finais.

Revista de Administração e Inovação, São Paulo, v. 9, n. 1, p.188-210, jan./mar. 2012. 


\section{ORIENTAÇÃO PARA O MERCADO (OPM)}

O conceito de OPM, apresentado na literatura acadêmica, reflete, em geral, a gestão de alinhamentos estratégicos das organizações demonstrando a amplitude de seu constructo. Apesar das suas muitas definições, a maioria coloca os clientes no centro das atenções da organização, e suas diferenças fundamentais se situam na forma como os autores consideram os processos de orientação para o mercado.

Narver e Slater (1990) analisaram a OPM pela ótica da cultura organizacional que visa criar valor superior aos clientes e desempenho superior para a organização por meio de três dimensões: orientação para o cliente, orientação para o concorrente e coordenação interfuncional. As duas primeiras incluem todas as atividades envolvidas na aquisição de informações sobre os consumidores e sobre os concorrentes do mercado-alvo e sua posterior divulgação por toda a organização. A visão do negócio como um todo também é destacada, já que é preciso entender as forças e as fraquezas, assim como as capacitações e as estratégias, atuais e no longo prazo.

A coordenação interfuncional baseia-se nas informações adquiridas e em esforços coordenados para criar valor superior e para dirigi-los aos clientes. Devido à criação de valor possuir uma natureza multidimensional e haver uma interdependência do marketing com as outras funções da empresa, seus procedimentos devem ser incorporados sistematicamente ao marketing estratégico da organização. Dessa maneira, segundo Narver e Slater (1990), a OPM pode estar centrada em atividades de aquisição e de difusão de informações de mercado e na criação coordenada e contínua de valor para o cliente.

No entanto, para Jaworski e Kohli (1993), tal argumento dependerá das condições do ambiente em que atua a empresa. Segundo os autores, a OPM pode estar relacionada a um conjunto de fatores internos que influenciam atividades antecedentes que aumentam ou bloqueiam a implantação do conceito de marketing pela organização. Dessa maneira, a OPM é composta por recursos que levam à geração e à divulgação de inteligência de mercado por toda a organização, referentes às atuais e às futuras necessidades dos clientes e à capacidade de respostas a elas. As atividades antecedentes são:

- comprometimento da alta administração, que possui papel crítico na formação de valores em uma organização;

- dinâmica interdepartamental, pela qual tanto os conflitos como o grau de contato direto formal ou informal entre funcionários de departamentos podem afetar a OPM;

- sistema organizacional, que deve estar fundamentado na formalização das normas e dos procedimentos, na centralização das decisões, na maneira como são departamentalizadas as atividades e os sistemas de recompensas, os quais definirão o comportamento dos colaboradores internos. 
Completando as duas propostas anteriores, Day (1994) afirma que o maior desafio é compreender como a OPM pode ser alcançada e mantida. A abordagem das capacidades emergentes da gestão estratégica, aliada à gestão de qualidade total, pode oferecer uma rica variedade nas formas de conceber programas de mudança que poderão promover a OPM. Desse modo, a empresa exerceria suas atividades de forma superior aos concorrentes e, assim, desenvolveria capacidades especiais. A ênfase nas capacidades, segundo Day (1994), pode ser classificada em três categorias, conforme apresentadas no Quadro 1.

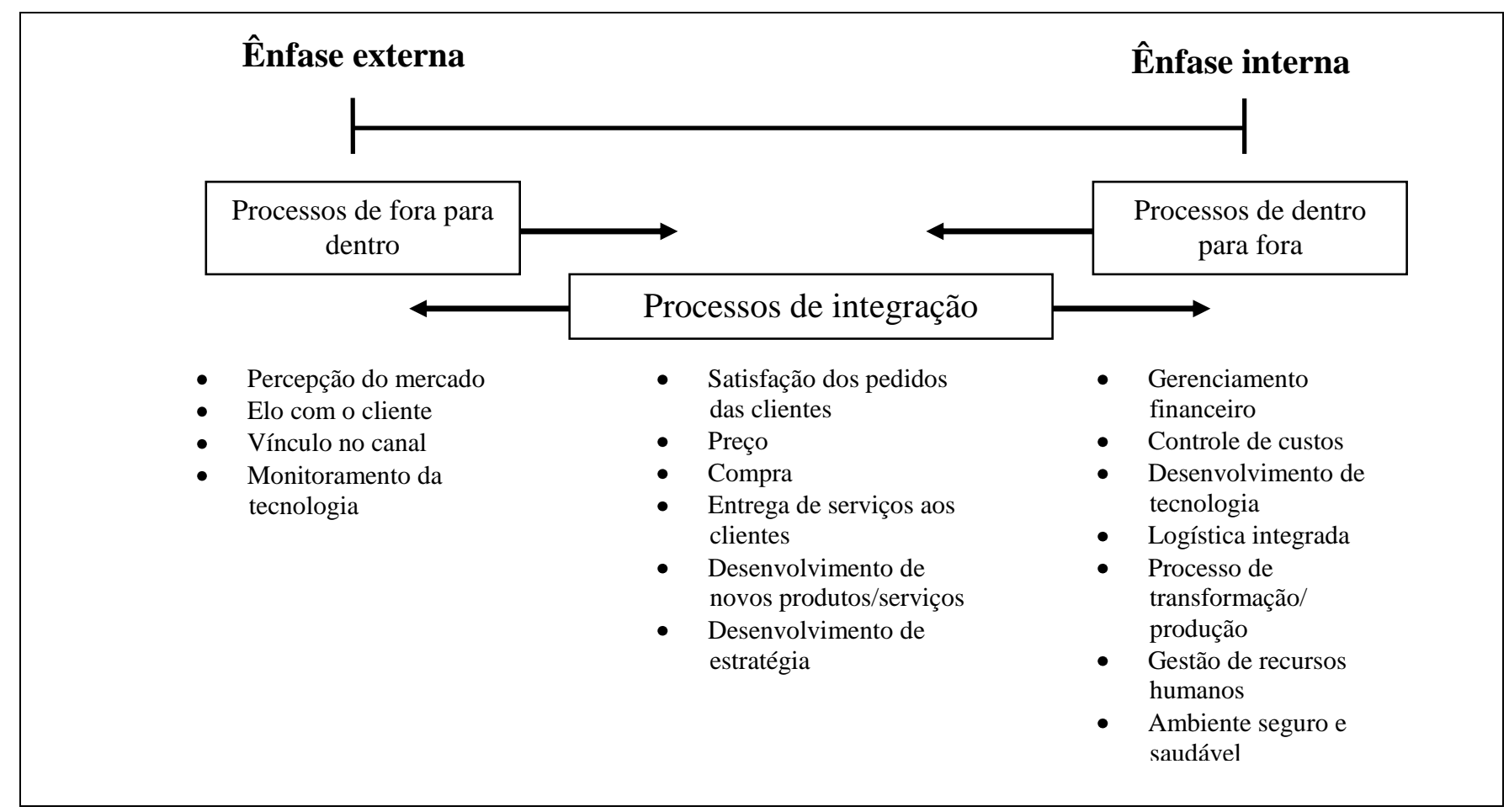

Quadro 1 - Classificação das capacidades.

Fonte: Adaptado de Day (1994).

Para o autor, capacidades são conjuntos complexos de habilidades e de conhecimentos, exercidos por meio de processos organizacionais que garantem a coordenação superior das atividades funcionais e permitem à organização aprender e melhorar continuamente. $\mathrm{O}$ desenvolvimento das capacidades se modifica conforme evoluem a organização e o ambiente em que atua e também na maneira como são estabelecidas as capacidades, os compromissos assumidos e as necessidades futuras.

Em um dos extremos do espectro contínuo, estão os processos de dentro para fora que podem ser ativados pelas necessidades do mercado, pelos desafios competitivos e pelas oportunidades externas. No outro extremo, estão as capacidades formadas por processos de fora para dentro que permitem à organização antecipar as necessidades do mercado e criar relações duradouras com clientes 
e com sua cadeia de valor. Abrangendo todas as capacidades, os processos de integração criam condições para estratégias de inovação, de preços, de compras e para estratégias de relacionamento com o cliente.

Adicionalmente, Deshpandé, Farley e Webster (1993) consideram que a perspectiva da cultura organizacional fundamenta o processo da gestão da informação e veem as organizações como sistemas de conhecimento. Estes permitirão entender o funcionamento da empresa, que será útil para compreender a orientação para o cliente. Para os autores, a OPM estabelece-se a partir de um conjunto de crenças cujo primeiro plano pertence aos interesses dos clientes. Nesse sentido, sob uma perspectiva gerencial, uma empresa orientada ao cliente inspira seus funcionários a medirem seus esforços e seus resultados em relação às necessidades e às expectativas dos clientes.

Para Whiteley (1991), as necessidades dos clientes precisam ser ensinadas, enfatizadas e reveladas constantemente por meio de uma análise de fatores divididos em sete grupos: (1) visão, empenho e clima; (2) alinhamento com clientes; (3) prontidão em localizar e em eliminar os problemas dos clientes; (4) uso e comunicação das informações dos clientes; (5) ir ao encontro de clientes; (6) competência, capacidade e poderes do pessoal; (7) aperfeiçoamento contínuo de processos e produtos. Com este conjunto de fatores, o autor procura demonstrar que o desempenho positivo da organização está relacionado com a cultura da empresa e com o foco no cliente. Assim, satisfação de clientes, cultura e crença podem relacionar-se positivamente com o desempenho da organização.

\subsection{PEQUENAS E MÉDIAS EMPRESAS E ORIENTAÇÃO PARA O MERCADO}

A literatura acadêmica tem revelado que é fundamental um alinhamento adequado entre uma orientação estratégica e um posicionamento no mercado devido ao seu impacto sobre o desempenho da empresa. Tal alinhamento é especialmente crucial para as PMEs, que possuem uma base de recursos limitada ao campo da competitividade, sugerindo que uma cultura orientada para o mercado pode ser um recurso importante para a organização de pequeno porte.

Para Li, Zhao, Tan e Liu (2008), o esforço em desenvolver uma OPM adequada deve partir da alta gestão como um componente importante a fim de melhorar seu perfil estratégico. Tal procedimento promove mudanças necessárias no ambiente organizacional e pode desenvolver novos modelos de comportamento do público interno. Mais adiante se verá como este fator é importante, já que, principalmente em uma PME, o público interno e a alta administração estão muito próximos facilitando a ligação entre a decisão estratégica realizada pela direção da empresa e a sua execução, normalmente realizada pelo restante da equipe (Moretti et al., 2010). Trata-se de um processo natural

Revista de Administração e Inovação, São Paulo, v. 9, n. 1, p.188-210, jan./mar. 2012. 
nas PMEs, já que procedimentos reconhecidos como eficientes se tornam consenso e se integram à gestão do negócio (Martin \& Martin, 2005). Dessa forma, o desempenho das PMEs refletir-se-ia a partir de uma orientação empreendedora impulsionada pelo aproveitamento das oportunidades de mercado, ou seja, por meio de uma OPM (Barker \& Sinkula, 2009).

Pesquisas apontam que PMEs com cultura orientada para o mercado têm uma relação positiva com a eficácia das vendas, com a rentabilidade e com o crescimento (Pelham, 2000; Pelham \& Wilson, 1996). Para Blankson e Cheng (2005), o desempenho das PMEs está relacionado com garantia da rentabilidade, com estabilidade financeira e com a realização dos objetivos do negócio. Porém, independentemente do tamanho da organização, a OPM ganha robustez a partir da percepção do mercado, da motivação e da preocupação com seus empregados, além do atendimento ao cliente.

Tal perspectiva parece consistente com as relações encontradas por Wiklund, Patzelt e Shepherd (2009), que apontam ser o crescimento de PMEs mediado por fundamentos empreendedores que, para além dos recursos escassos, gerenciam suas empresas por meio de uma perspectiva estratégica alinhada ao dinamismo do ambiente em que atuam.

Há, na literatura científica, diferentes maneiras de conceituar e de medir o desempenho das empresas. Para Perin e Sampaio (2004), a complexidade e a multidimensionalidade do desempenho têm proporcionado aos pesquisadores a conceitualização do desempenho empresarial de uma forma ampla que vai desde sinônimo de eficiência até resultados financeiros da empresa. Duchessi e Chengalur-Smith (2008) e Zhang (2000) conceituam desempenho a eficiência de métodos de gestão. Kaplan e Norton (1996) enfatizam a necessidade do equilíbrio entre os indicadores financeiros e as métricas não financeiras na aferição do desempenho de uma empresa.

\subsection{RESTAURANTES POR QUILO: PEQUENAS EMPRESAS NO MERCADO FOOD SERVICE}

As PMEs têm um papel fundamental no contexto econômico brasileiro, possuindo substancial importância econômica e inegável capacidade de gerar contrapartidas sociais (Moyses \& Pereira, 2008). O crescente segmento food service, comida preparada ou consumida fora do lar, o qual concentra, em grande parte, muitas pequenas empresas, possui pontual importância na economia brasileira, com cerca de 1,3 milhão de pontos de venda, espalhados por mais de 6 mil municípios em todo o território nacional. Estima-se que sejam produzidos cerca de 100 milhões de refeições diárias, volume que, anualmente, se somada toda a cadeia que ele movimenta, superou em 2008 os R\$ 145 bilhões em faturamento, que representou 9,3\% do Produto Interno Bruto (PIB) nacional (Associação Brasileira das Indústrias da Alimentação [ABIA], 2011).

Revista de Administração e Inovação, São Paulo, v. 9, n. 1, p.188-210, jan./mar. 2012. 
A gestão de restaurantes tem recebido certo aprimoramento nos últimos tempos e há uma tendência à formalização do setor. Segundo dados da revista Pequenas Empresas \& Grandes Negócios (PEGN), Santos (2010) afirma que, em pesquisa realizada pela Associação Nacional dos Restaurantes (ANR), $80 \%$ dos estabelecimentos têm nutricionistas ou técnicos especializados; $81 \%$ recebem o apoio de consultorias; 94\% dos restaurantes afirmam ter software de gestão; 89\% realizam pesquisa de satisfação; 75\% mantêm cadastro de sua clientela e $61 \%$ dos pesquisados possuem programas de capacitação para seus funcionários, apesar de apontarem problemas com custos da matéria-prima, com encargos tributários e com custos trabalhistas, nesta ordem.

Embora para a Associação Brasileira de Bares e Restaurantes (Abrasel) ocorra progressiva profissionalização do setor, de acordo com Ibelli (2006), 60\% dos restaurantes abertos na cidade de São Paulo fecham as portas no primeiro ano de atividade. Em pesquisa com 400 restaurantes da cidade de São Paulo, apenas 50\% deles tinham mais de 3 anos e somente $18 \%$ dos restaurantes superavam os 10 anos de atividades. O ambiente, neste segmento em particular, é extremamente competitivo e está em constante mudança em direção a elevado padrão; há poucos fatores limitadores à entrada no mercado, e o grande desafio está no conhecimento e no aprimoramento contínuo (Maricato, 2005).

Inspirado nas cantinas italianas que vendiam massa por peso, os restaurantes por quilo surgiram em meados da década de 1980, na cidade de São Paulo, e logo se difundiram por todo o país, fazendo parte da cultura brasileira da alimentação fora do lar, principalmente no período do almoço, tendo como clientes os mais diversos perfis de consumidores. Segundo Donato (2009), um dos pontos positivos para o crescimento rápido deste tipo de negócio foi ter permitido ao consumidor uma redução no tempo de espera de atendimento, bem como poder escolher entre uma grande variedade de pratos, de saladas, de carnes e de massas, pagando apenas o consumo do peso. Esta foi a marca da evolução; as opções oferecidas aos clientes se tornaram cada vez maiores e melhores.

\subsection{MODELO DE ANÁLISE DE IMPORTÂNCIA E DESEMPENHO (IPA)}

Uma parcela considerável de administradores de PMEs consegue atribuir graus de importância às atividades estratégicas desenvolvidas em sua gestão. Porém existem dificuldades em traduzir e em compreender o significado da relação entre as atividades desenvolvidas pela empresa e seu real desempenho. Analisados isoladamente, a importância e os dados de desempenho podem não ser tão significativos quando estudados simultaneamente (Graf, Hemmasi, \& Nielsen, 1992), sendo necessário mapeá-los e analisá-los em conjunto (Ainin \& Hishan, 2008).

Uma possibilidade de análise conjunta é oferecida pelo modelo de análise de importância $\mathrm{x}$ desempenho (IPA), amplamente aplicado a diversas áreas como serviços médicos, viagens e turismo,

Revista de Administração e Inovação, São Paulo, v. 9, n. 1, p.188-210, jan./mar. 2012. 
tráfego e transportes, entre outras (Lin, Chan, \& Tsai, 2009). Tal análise pode ser usada para avaliar as vantagens competitivas de uma organização no mercado, identificar oportunidades de melhoria e orientar o desenvolvimento de projetos estratégicos para uma empresa (Deng, 2007), sendo capaz de orientar estrategicamente a melhor alocação dos recursos disponíveis dela.

A IPA foi introduzida por Martilla e James (1977), em uma pesquisa de marketing, com o propósito de compreender a satisfação de clientes (medidas por atributos considerados importantes) de concessionárias de automóveis comparadas com seu desempenho. Os atributos de importância e as análises de desempenho devem orientar-se na identificação dos atributos relevantes para a situação a ser analisada. A partir dos dados obtidos por meio de um questionário, plotam-se seus valores médios em um sistema matricial bidimencional no qual a importância é representada no eixo Y e o “desempenho" é representado no eixo X. A Figura 1 apresenta o modelo.

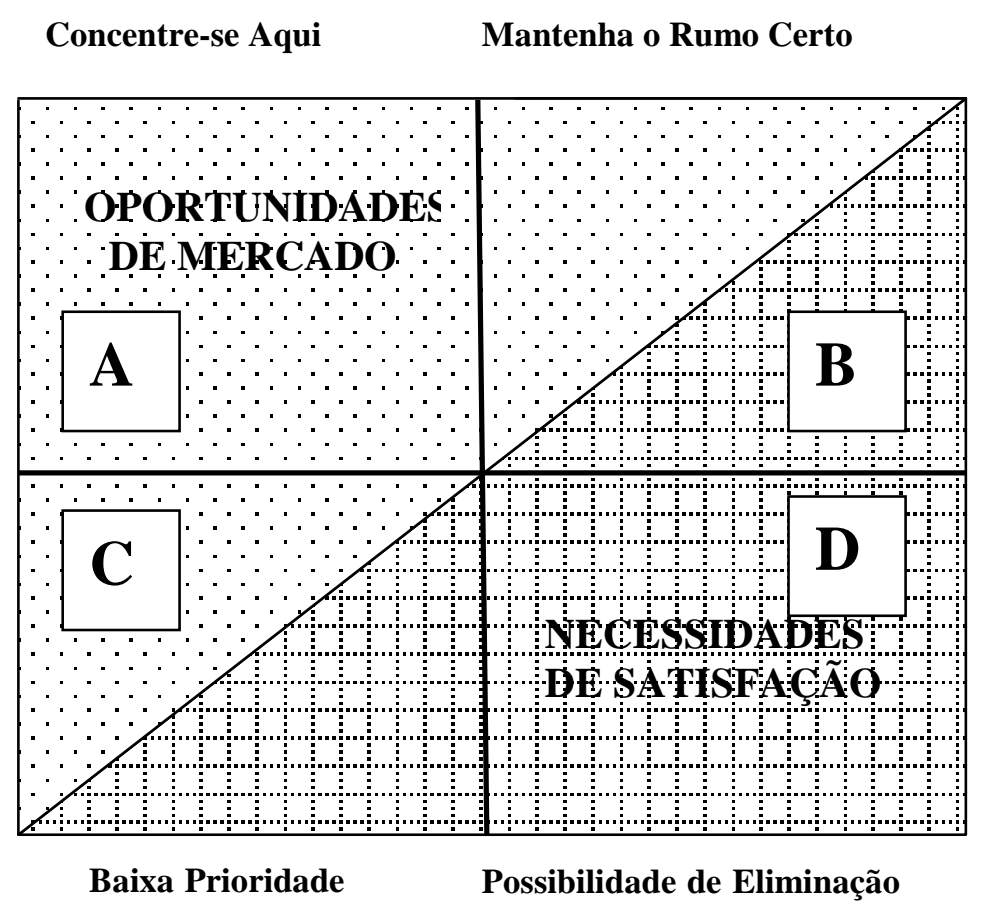

Figura 1 - Modelo IPA.

Fonte: Adaptado de Hawes (1985) e Martilla e James (1977).

Os dados são mapeados em quatro quadrantes. De acordo com Martilla e James (1977), no quadrante A a importância é alta, mas o desempenho é baixo; este quadrante é denominado Concentre-se Aqui, indicando que os sistemas existentes necessitam de urgente ação corretiva e, portanto, a eles deve ser dada prioridade. O quadrante B apresenta alta importância e alto desempenho, indicando que os sistemas existentes têm pontos fortes e devem ser mantidos. Esta categoria é rotulada como Mantenha o Rumo Certo. No quadrante C, as categorias de pouca importância e os itens de 
baixo desempenho fazem com que ele seja denominado Baixa Prioridade. Atributos com essa avaliação não representam uma ameaça e podem ser candidatos à interrupção. Finalmente, o quadrante D representa baixa importância e alto desempenho, sugerindo que os recursos investidos nestas atividades podem ser desviados para outros sistemas. Esta categoria é rotulada de Possibilidade de Eliminação.

Extensões do mapeamento IPA incluem a adição de uma linha inclinada a 45 graus para destacar as regiões de prioridades diferentes, também conhecida como isoavaliação ou linha de prioridade iso, na qual a importância é igual ao desempenho. Qualquer atributo abaixo da linha deve ter prioridade, já que são necessidades que devem ser saciadas, enquanto um atributo acima da linha indica o contrário, além de apresentar oportunidades no mercado (Hawes, 1985).

As dificuldades na interpretação da importância das atividades desenvolvidas pela empresa podem estar relacionadas às questões que envolvem a capacidade de percepção de seus gestores e a legitimação de tais atributos com o seu real desempenho. Bacon (2003) buscou evidências para validar as informações arbitradas no âmbito da IPA; sua conclusão foi que as medidas ditas diretas são a melhor maneira para quantificar a importância, em vez de outras como as obtidas por meio de coeficiente de regressão, de modo que as medidas aqui desenvolvidas parecem ser adequadas para representação na matriz bidimensional.

\section{PROCEDIMENTOS METODOLÓGICOS}

O problema da pesquisa foi centrado em averiguar as atividades de marketing que restaurantes por quilo com mais de 10 anos de existência na cidade de São Paulo desenvolvem a fim de promover um desempenho superior no ambiente em que atuam. A investigação de campo foi desenvolvida em duas fases. Inicialmente, realizou-se um estudo exploratório por meio de um pré-teste em duas empresas da população de restaurantes por quilo, utilizando-se um roteiro de entrevistas com questões abertas, semiestruturadas e em profundidade (Lakatos \& Marconi, 1985). Nesta etapa da pesquisa foram realizadas entrevistas com os gestores dos restaurantes. Posteriormente, o instrumento já aperfeiçoado foi aplicado junto a gestores considerados como pessoas com experiência das demais organizações e responsáveis por gerar as fontes de informação do estudo.

O estudo exploratório, segundo Vergara (2006), atendeu também à intenção inicial de se obter maior conhecimento do tema específico, pois, apesar de existir uma farta literatura sobre OPM, eles são escassos em PMEs e, principalmente, no setor food service. Este estudo pôde ser implementado buscando-se informações em diversas fontes: dados secundários (aquilo que já foi produzido por 
outrem, como a revisão bibliográfica aqui apresentada), pesquisa por observação, pessoas informadas, pessoas com experiência e estudo de caso.

Essa fase foi complementada por meio de visitas dissimuladas aos restaurantes a fim de observar as práticas de marketing, o atendimento ao cliente, o serviço, a qualidade do produto, as táticas de preços, as atividades promocionais, a aparência do pessoal e o ambiente e suas instalações (Appiah-Adu, 1998). Estes procedimentos permitiram a identificação de atividades de marketing consideradas apropriadas a OPM em PMEs, segundo referências da literatura.

A primeira fase possibilitou a elaboração de um instrumento de pesquisa, estruturado em um questionário condensado em dezesseis itens de atividades ou de atributos com orientação para o mercado. A razão para a condensação dos itens foi reduzir a complexidade do questionário. De outra maneira, poder-se-iam incluir outros fatores ou atributos percebidos durante a pesquisa exploratória, o que serviria para proporcionar uma visão diferente ou para melhorar as consistências das variáveis estudadas. No entanto, optou-se por fortalecer o conjunto dos atributos mais citados durante as entrevistas semiestruturadas.

O questionário, a ser aplicado na segunda fase da pesquisa, foi composto por duas seções: a primeira foi relacionada ao grau de importância dada a cada atributo ou atividade desenvolvida pela gestão do restaurante e a segunda convidava os entrevistados a fazer uma avaliação acerca do desempenho percebido do restaurante em relação aos concorrentes diretos no mercado em que atuam. Solicitava-se aferir valores em uma escala Likert com cinco pontos, como segue: de (1) não é importante a (5) muito importante, para o grau de importância; de (1) ruim a (5) excelente, para o grau de desempenho.

A segunda fase da pesquisa desenvolveu-se com um estudo de múltiplos casos (Yin, 2005), que teve por objetivo proceder à investigação das nove unidades de restaurantes por quilo distribuídos em diferentes faixas de volume de refeições diárias servidas (de 200 a 1000) e práticas de preços (de R $\$$ $18,00$ a $\mathrm{R} \$ 32,00)$ que não possuíssem relação direta com o volume de vendas, a fim de garantir a inexistência de um provável viés. A amostra pesquisada está distribuída conforme o Quadro 2.

\begin{tabular}{|l|l|l|}
\hline Casos Estudados & $\begin{array}{l}\text { Quantidade Média de } \\
\text { Refeições Servidas por Dia }\end{array}$ & $\begin{array}{l}\text { Preço por Kilo } \\
(\mathbf{R} \$ \mathbf{)}\end{array}$ \\
\hline A Casa da Vovó & 200 & 27,00 \\
\hline Restaurante Milenium & 250 & 24,00 \\
\hline Restaurante Peniche & 350 & 23,90 \\
\hline Kero Kilo Restaurante & 400 & 31,90 \\
\hline Linka Restaurante & 500 & 26,00 \\
\hline Lanchonete Karem & 700 & 18,00 \\
\hline Maktub Restaurante & 800 & 32,00 \\
\hline Restaurante Red Roof & 900 & 29,00 \\
\hline Sete Grill & 1000 & 30,00 \\
\hline
\end{tabular}

Revista de Administração e Inovação, São Paulo, v. 9, n. 1, p.188-210, jan./mar. 2012. 
Quadro 2 - Unidades de estudo.

Fonte: Elaborado pelos autores.

A seleção das unidades de estudo foi criteriosa na escolha dos casos de restaurantes por quilo que ultrapassaram 10 anos de atividades, localizados no centro expandido da cidade de São Paulo, cujo perfil do público frequente é composto por homens e mulheres das classes A e B. Todas as organizações pesquisadas possuíam atributos tangíveis semelhantes e tiveram como referência, entre outros, a fachada, os toaletes, a decoração e o entorno geográfico (Chen \& Chen, 2010).

Pôde-se, então, aplicar o questionário, coletar os dados e desenvolver a análise, conforme sustentado por Bacon (2003) e Martilla e James (1977). Os resultados obtidos foram plotados segundo o modelo IPA e apresentados na Figura 1. As atividades e os atributos estabelecidos nas dezesseis questões foram analisados a partir de seu posicionamento nos quadrantes por meio das respectivas médias dadas à importância e ao desempenho e serviram para compreender o status quo da percepção dos gestores das PMEs desta pesquisa quanto aos processos organizacionais que se orientam na geração de valor para seus clientes e para o negócio e seu respectivo desempenho. A IPA serviu também para propor a estratégia da continuidade ou da reorientação destas atividades, além de proporcionar dados que possam indicar vínculos entre a gestão das unidades estudadas e a OPM referenciada.

\section{PRINCIPAIS RESULTADOS E DISCUSSÃO}

Esta pesquisa teve como objetivo verificar a relação entre a OPM e as atividades que restaurantes por quilo desenvolvem em seus processos organizacionais ao longo do tempo para dirimir riscos e para criar valor para o negócio. A partir da validação dos entrevistados para a importância e para o desempenho destas atividades, obteve-se uma nota média por meio de um questionário. Posteriormente, observou-se a existência de uma diferença entre as médias dadas à importância e ao desempenho.

A construção do modelo IPA esteve atrelada ao nível de compreensão das atividades e dos atributos de cada questão pelos respondentes. No entanto, a importância dada às atividades e ao desempenho percebido apresentou diferenças entre as expectativas do desempenho das atividades. Convém lembrar que estas atividades foram assumidas como essenciais para a criação de valor para o negócio e para o efetivo desempenho percebido em seu ambiente de atuação. O Quadro 3 mostra as diferenças ou gaps constatados.

A análise de diferenças ou gaps é referenciada em Parasuraman, Zeithaml e Berry (1985) a

Revista de Administração e Inovação, São Paulo, v. 9, n. 1, p.188-210, jan./mar. 2012. 
partir das expectativas do serviço esperado e recebido pelos clientes. Da mesma forma, esta lacuna, no presente estudo, pode contribuir com o aprofundamento da análise e reforçar os resultados esperados pela gestão da empresa. As atividades que apresentaram médias mais elevadas em relação à importância (destacadas em cinza-escuro no Quadro 3) estavam diretamente relacionadas aos atributos satisfação e confiança dos clientes. Porém este grupo de atividades apresentou uma lacuna relativamente alta em relação ao desempenho percebido.

\begin{tabular}{|l|c|c|c|}
\hline Atividades & Importância & Desempenho & Lacuna \\
\hline 1-Preparo do cardápio & 4,67 & 4,11 & $-0,56$ \\
\hline 2-Pesquisar o cardápio da concorrência & 3,11 & 2,11 & $-1,00$ \\
\hline 3-Pesquisar as tendências de mercado & 3,89 & 2,78 & $-1,11$ \\
\hline 4-Pesquisar outras fontes para montar o cardápio & 4,22 & 3,22 & $-1,00$ \\
\hline $\begin{array}{l}\text { 5-Atender as solicitações de pratos ao gosto do } \\
\text { cliente }\end{array}$ & 4,56 & 4,11 & $-0,45$ \\
\hline 6-Uso de banco de dados dos clientes & 2,33 & 1,00 & $-1,33$ \\
\hline 7-Conseguir informações dos clientes & 4,22 & 3,44 & $-0,78$ \\
\hline 8a-Tarefas/atividades operacionais & 4,78 & 4,00 & $-0,78$ \\
\hline 8b-Tarefas/atividades administrativas & 4,67 & 4,00 & $-0,67$ \\
\hline 9-Medir a satisfação dos clientes & 4,89 & 3,67 & $-1,22$ \\
\hline $\begin{array}{l}\text { 10-Colaboradores contribuem para satisfação do } \\
\text { cliente }\end{array}$ & 4,89 & 3,33 & $-1,56$ \\
\hline $\begin{array}{l}\text { 11-Oferecer estímulos para os funcionários } \\
\text { contribuírem para a satisfação dos consumidores }\end{array}$ & 4,22 & & $-1,22$ \\
\hline 12-Colaboradores receberem treinamentos & 4,11 & 3,44 & $-0,67$ \\
\hline 13-Comunicação com os clientes & 4,67 & 3,56 & $-1,11$ \\
\hline 14-Estabelecer confiança na relação cliente/empresa & 5,00 & 4,00 & $-1,00$ \\
\hline $\begin{array}{l}\text { 15-Praticar ações que deem satisfação acima do que } \\
\text { os clientes esperam }\end{array}$ & 4,22 & 3,44 & $-0,78$ \\
\hline 16-Oferecer brindes eventuais para clientes & 3,78 & 2,44 & $-1,34$ \\
\hline \begin{tabular}{l} 
Qudro 3 Avaliacão do desenp \\
\hline
\end{tabular}
\end{tabular}

Quadro 3 - Avaliação do desempenho, importância e lacuna (gap).

Fonte: Elaborado pelos autores.

$\mathrm{Na}$ ordem, importância alta e desempenho relativo, as atividades foram: Estabelecer confiança na relação cliente/empresa (5,00/4,00); Colaboradores contribuem para satisfação do cliente $(4,89 / 3,33)$; Medir a satisfação dos clientes $(4,89 / 3,67)$. Pode-se observar, dada a importância à satisfação e confiança do cliente, que há uma necessidade constante de aprimoramento nas atividades desenvolvidas neste campo.

Observa-se, também, importância alta dada às atividades operacionais como: Tarefas/atividades Operacionais (4,78/4,00); Atender as solicitações de pratos ao gosto do cliente $(4,56 / 4,11)$; Preparo do 
Cardápio $(4,67 / 4,11)$ e Tarefas/atividades Administrativas $(4,67 / 4,00)$. O relacionamento direto com o cliente foi apontado como fator de grande importância para o sucesso do negócio: Conseguir informações dos clientes $(4,22 / 3,44)$ e outras fontes de Comunicação com o cliente $(4,67 / 3,56)$ obtiveram notas acima da média. Tais atividades foram apontadas como capazes de gerar um maior desempenho a partir de treinamentos com seus funcionários.

Tanto é que a disseminação de informações por meio de Treinamento com os colaboradores internos $(4,11 / 3,54)$ e consequentes Programas de recompensas $(4,22 / 3,00)$ são dadas importâncias relativamente altas. O desenvolvimento de capacidades que irão colaborar na criação de valor e satisfação do cliente, apesar de ser reconhecido como fator importante, está aquém das expectativas dos próprios gestores, que alegam falta de recursos para implantar e para controlar sistemas formalizados e coordenados. No entanto, tais procedimentos acontecem, na maioria das vezes, de maneira informal e contínua.

As atividades e os atributos até aqui referenciados foram plotados no quadrante B superior direito da matriz bidimensional, onde o ponto cruz das coordenadas se deu no nível 3 (Bacon, 2003). A importância média destes itens é superior à média da importância da ordenada e, por isso, devem ser rotulados como Mantenha o rumo certo (Martilla \& James, 1977).

Por outro lado, os itens relacionados ao quadrante A superior esquerdo foram: Oferecer brindes eventuais para clientes $(3,78 / 2,44)$, que apresentou pouca importância e baixo desempenho, assim como a busca de informações no mercado e nos concorrentes. Às atividades Pesquisar o cardápio da concorrência $(3,11 / 2,11)$ e Pesquisar as tendências de mercado $(3,89 / 2,78)$ foram dadas notas baixas para importância e para desempenho (destacados na gradação cinza-claro no Quadro 3). Configura-se, assim, que a importância média para tais atividades ou atributos continua sendo superior à média da importância da ordenada; porém o desempenho desses itens em relação à importância é relativamente baixo, o que faz com que sejam rotulados de Concentre-se Aqui, indicando que, quanto maior a distância do cruzamento das coordenadas, maior a urgência de melhoria (Martilla \& James,1977).

Apesar da relativa baixa importância e desempenho dados às perguntas referentes às pesquisas da concorrência e às tendências de mercado para desenvolver o cardápio, este é considerado, entre os entrevistados, um dos maiores fatores do sucesso para as empresas. Por se tratar, na maioria, de empresas familiares, destaca-se sua origem nas receitas caseiras e de família, e, quase sempre, sob a coordenação de um dos donos e sob a supervisão de um responsável técnico. Este fato é comprovado, já que as fontes de informações que não provêm diretamente do mercado para desenvolver o cardápio (Pesquisar outras fontes para montar o cardápio) têm recebido maior atenção do que observar os produtos in loco na concorrência. Estas fontes provêm, em geral, de conhecimentos e de habilidades 
tácitos dos envolvidos nos processos organizacionais e, em sua maioria, se transformam em pratos para os cardápios os quais são elaborados e testados inicialmente dentro dos lares ou até sugeridos pelos clientes mais íntimos.

No quadrante $\mathrm{C}$ inferior esquerdo da matriz bidimensional aparece o Uso de banco de dados de clientes $(2,33 / 1,00)$, do qual tanto a importância quanto o desempenho foram abaixo da média ou quase nulos. As organizações estudadas ainda não fazem uso de softwares para cadastro e para pesquisa de satisfação dos clientes, como apontou a pesquisa publicada na revista PEGN (Santos, 2010), mas focam suas relações buscando informações a partir de certa intimidade e um clima familiar com os comensais. Apesar de existir uma diferença negativa entre desempenho e importância, a média dada à importância de tal atividade é inferior à importância média, o que faz com que seja rotulada de Baixa prioridade (Martilla \& James, 1977).

Observa-se que, no quadrante D, posicionado na parte inferior direita da matriz bidimensional, região onde o desempenho é maior que a importância, não foi plotada nenhuma atividade ou atributo, sugerindo que os recursos destas PMEs são bem alocados, não sendo necessária a eliminação dos processos organizacionais constantes no questionário (Martilla \& James, 1977).

Por meio da matriz bidimensional IPA, apresentada na Figura 2, pode-se perceber que essas organizações possuem, em sua maioria, atividades com grande importância e com alto desempenho no mercado em que atuam, desenvolvendo atributos de posicionamento e de relacionamento que são considerados eficazes e que devem ser mantidos e aprimorados. 


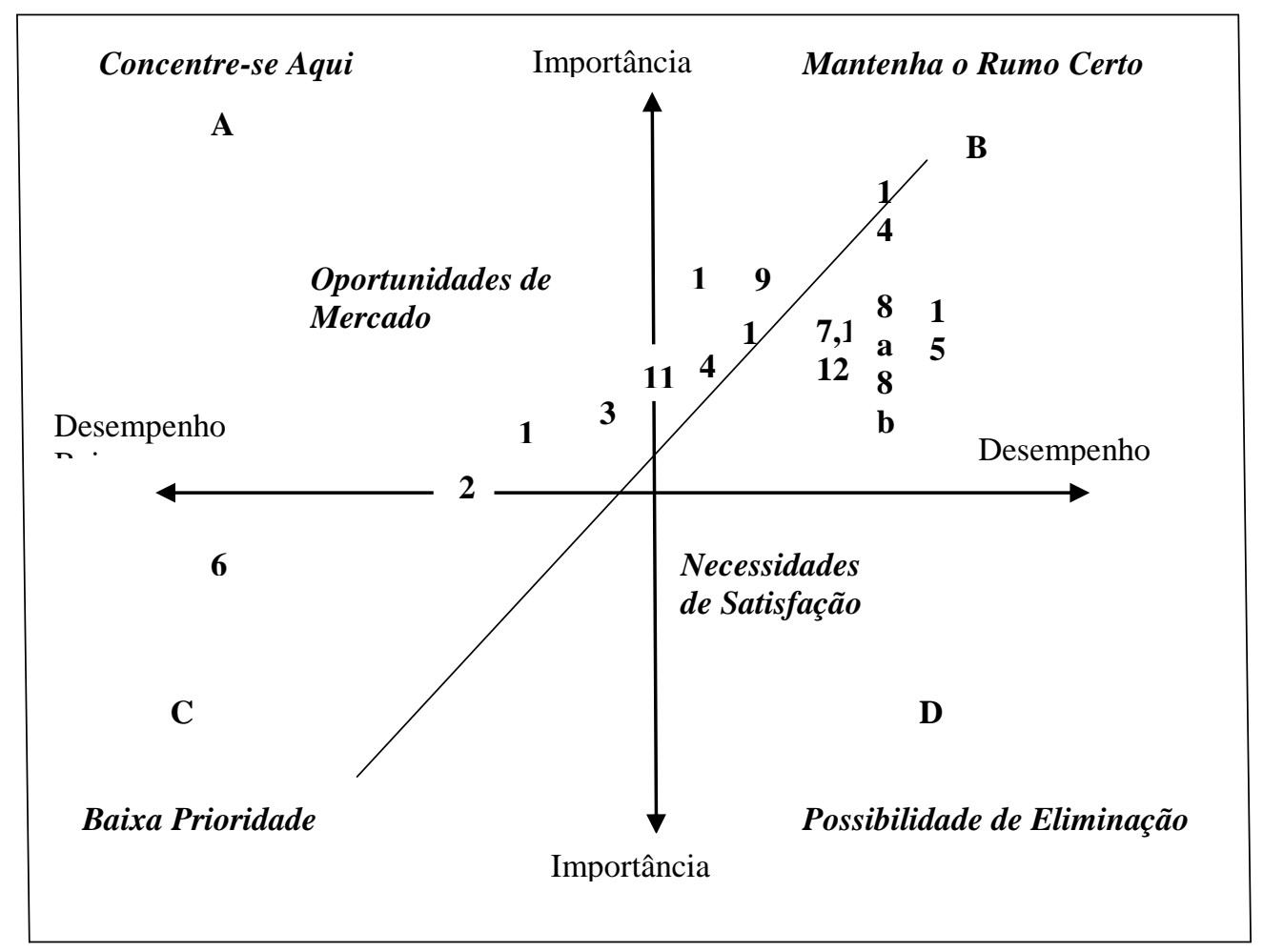

Figura 2 - Análise de importância $\mathrm{x}$ desempenho de restaurantes por quilo da cidade de São Paulo.

Fonte: Elaborado pelos autores (2010).

A partir da análise das extensões da linha inclinada a 45 graus, a isoavaliação ou linha de prioridade iso aponta que essas empresas podem aprimorar sua gestão com os recursos humanos disponíveis, estimulando-os na satisfação e na criação de valor aos consumidores, assim como as tendências de mercado e as informações da concorrência são oportunidades que elas podem obter no ambiente em que atuam. O Quadro 4 resume a relação das atividades originadas a partir da pesquisa exploratória e os atributos encontrados na literatura que amparou este estudo. 


\begin{tabular}{|c|c|c|c|c|}
\hline Questionário & $\begin{array}{l}\text { Componentes } \\
\text { comportamentai } \\
\text { s (Naver e } \\
\text { Slater, (1990) }\end{array}$ & $\begin{array}{l}\text { Antecedentes da } \\
\text { OPM (Jaworski e } \\
\text { Kohli, 1993) }\end{array}$ & $\begin{array}{l}\text { Categorias das } \\
\text { Capacidades } \\
\text { Day (1994) }\end{array}$ & $\begin{array}{c}\text { Fatores da } \\
\text { orientação para o } \\
\text { Cliente Whiteley } \\
\text { (1997) }\end{array}$ \\
\hline 1-Preparo do Cardápio & $\begin{array}{l}\text { Coordenação } \\
\text { Multifuncional }\end{array}$ & $\begin{array}{c}\text { Dinâmica } \\
\text { Interdepartamental }\end{array}$ & $\begin{array}{l}\text { Processos } \\
\text { internos }\end{array}$ & $\begin{array}{l}\text { Alinhamento } \\
\text { Estratégico com os } \\
\text { clientes }\end{array}$ \\
\hline $\begin{array}{l}\text { 2-Pesquisar o Cardápio da } \\
\text { Concorrência }\end{array}$ & $\begin{array}{l}\text { Orientação para } \\
\text { os Concorrentes }\end{array}$ & $\begin{array}{c}\text { Dinâmica } \\
\text { Interdepartamental }\end{array}$ & $\begin{array}{l}\text { Processos } \\
\text { externos }\end{array}$ & $\begin{array}{l}\text { Aperfeiçoamento } \\
\text { contínuo de } \\
\text { processo/produto }\end{array}$ \\
\hline $\begin{array}{l}\text { 3-Pesquisar as tendências de } \\
\text { Mercado }\end{array}$ & $\begin{array}{l}\text { Orientação para } \\
\text { os Concorrentes }\end{array}$ & $\begin{array}{c}\text { Dinâmica } \\
\text { Interdepartamental }\end{array}$ & $\begin{array}{l}\text { Processos } \\
\text { externos }\end{array}$ & $\begin{array}{l}\text { Aperfeiçoamento } \\
\text { contínuo de } \\
\text { processo/produto }\end{array}$ \\
\hline $\begin{array}{l}\text { 4-Pesquisar outras fontes para } \\
\text { montar o cardápio }\end{array}$ & $\begin{array}{l}\text { Coordenação } \\
\text { Multifuncional }\end{array}$ & $\begin{array}{c}\text { Dinâmica } \\
\text { Interdepartamental }\end{array}$ & $\begin{array}{l}\text { Processos } \\
\text { externos }\end{array}$ & $\begin{array}{l}\text { Aperfeiçoamento } \\
\text { contínuo de } \\
\text { processo/produto }\end{array}$ \\
\hline $\begin{array}{l}\text { 5-Atender as solicitações de } \\
\text { pratos ao gosto do cliente }\end{array}$ & $\begin{array}{l}\text { Orientação para o } \\
\text { Cliente }\end{array}$ & $\begin{array}{l}\text { Estrutura e Sistema } \\
\text { Organizacional }\end{array}$ & $\begin{array}{l}\text { Processos } \\
\text { de união }\end{array}$ & $\begin{array}{c}\text { Prontidão em } \\
\text { localizar/eliminar } \\
\text { os problemas }\end{array}$ \\
\hline $\begin{array}{l}\text { 6-Uso de banco de dados dos } \\
\text { clientes }\end{array}$ & $\begin{array}{l}\text { Orientação para o } \\
\text { Cliente }\end{array}$ & $\begin{array}{l}\text { Estrutura e Sistema } \\
\text { Organizacional }\end{array}$ & $\begin{array}{l}\text { Processos } \\
\text { internos }\end{array}$ & $\begin{array}{l}\text { Uso e comunicação } \\
\text { das informações } \\
\text { dos clientes }\end{array}$ \\
\hline $\begin{array}{l}\text { 7-Conseguir informações dos } \\
\text { clientes }\end{array}$ & $\begin{array}{l}\text { Orientação para o } \\
\text { Cliente }\end{array}$ & $\begin{array}{c}\text { Dinâmica } \\
\text { Interdepartamental }\end{array}$ & $\begin{array}{l}\text { Processos } \\
\text { de união }\end{array}$ & $\begin{array}{l}\text { Ir ao encontro dos } \\
\text { clientes }\end{array}$ \\
\hline $\begin{array}{l}\text { 8a-Tarefas/atividades } \\
\text { Operacionais }\end{array}$ & $\begin{array}{l}\text { Coordenação } \\
\text { Multifuncional }\end{array}$ & $\begin{array}{c}\text { Dinâmica } \\
\text { Interdepartamental }\end{array}$ & $\begin{array}{l}\text { Processos } \\
\text { internos }\end{array}$ & $\begin{array}{c}\text { Visão } \\
\text { organizacional, } \\
\text { empenho e clima }\end{array}$ \\
\hline $\begin{array}{l}\text { 8b-Tarefas/atividades } \\
\text { Administrativas }\end{array}$ & $\begin{array}{l}\text { Coordenação } \\
\text { Multifuncional }\end{array}$ & $\begin{array}{l}\text { Comprometimento da } \\
\text { Alta Administração }\end{array}$ & $\begin{array}{l}\text { Processos } \\
\text { internos }\end{array}$ & $\begin{array}{c}\text { Visão } \\
\text { organizacional, } \\
\text { empenho e clima }\end{array}$ \\
\hline $\begin{array}{l}\text { 9-Medir a satisfação dos } \\
\text { clientes }\end{array}$ & $\begin{array}{l}\text { Orientação para o } \\
\text { Cliente }\end{array}$ & $\begin{array}{c}\text { Dinâmica } \\
\text { Interdepartamental }\end{array}$ & $\begin{array}{l}\text { Processos } \\
\text { de união }\end{array}$ & $\begin{array}{l}\text { Ir ao encontro dos } \\
\text { clientes }\end{array}$ \\
\hline $\begin{array}{l}\text { 10-Colaboradores contribuem } \\
\text { para satisfação do cliente }\end{array}$ & $\begin{array}{l}\text { Orientação para o } \\
\text { Cliente }\end{array}$ & $\begin{array}{c}\text { Dinâmica } \\
\text { Interdepartamental }\end{array}$ & $\begin{array}{l}\text { Processos } \\
\text { de união }\end{array}$ & $\begin{array}{l}\text { Prontidão em } \\
\text { localizar/eliminar } \\
\text { os problemas }\end{array}$ \\
\hline $\begin{array}{l}\text { 11-Oferecer estímulos para os } \\
\text { funcionários contribuírem para } \\
\text { a satisfação dos consumidores }\end{array}$ & $\begin{array}{l}\text { Coordenação } \\
\text { Multifuncional }\end{array}$ & $\begin{array}{l}\text { Comprometimento da } \\
\text { Alta Administração }\end{array}$ & $\begin{array}{l}\text { Processos } \\
\text { internos }\end{array}$ & $\begin{array}{c}\text { Visão } \\
\text { organizacional, } \\
\text { empenho e clima }\end{array}$ \\
\hline $\begin{array}{l}\text { 12-Colaboradores receberem } \\
\text { treinamentos }\end{array}$ & $\begin{array}{l}\text { Coordenação } \\
\text { Multifuncional }\end{array}$ & $\begin{array}{c}\text { Estrutura e Sistema } \\
\text { Organizacional }\end{array}$ & $\begin{array}{l}\text { Processos } \\
\text { internos }\end{array}$ & $\begin{array}{c}\text { Competência, } \\
\text { capacidade e } \\
\text { poderes do pessoal }\end{array}$ \\
\hline $\begin{array}{l}\text { 13-Comunicação com os } \\
\text { clientes }\end{array}$ & $\begin{array}{l}\text { Orientação para o } \\
\text { Cliente }\end{array}$ & $\begin{array}{c}\text { Dinâmica } \\
\text { Interdepartamental }\end{array}$ & $\begin{array}{l}\text { Processos } \\
\text { de união }\end{array}$ & $\begin{array}{l}\text { Ir ao encontro dos } \\
\text { clientes }\end{array}$ \\
\hline $\begin{array}{l}\text { 14- Estabelecer confiança na } \\
\text { relação cliente/empresa }\end{array}$ & $\begin{array}{l}\text { Coordenação } \\
\text { Multifuncional }\end{array}$ & $\begin{array}{c}\text { Dinâmicas } \\
\text { Interdepartamental }\end{array}$ & $\begin{array}{l}\text { Processos } \\
\text { de união }\end{array}$ & $\begin{array}{c}\text { Visão } \\
\text { Organizacional, } \\
\text { empenho e clima }\end{array}$ \\
\hline $\begin{array}{l}\text { 15-Praticar ações que deem } \\
\text { satisfação acima do que os } \\
\text { clientes esperam }\end{array}$ & $\begin{array}{l}\text { Orientação para o } \\
\text { Cliente }\end{array}$ & $\begin{array}{c}\text { Dinâmica } \\
\text { Interdepartamental }\end{array}$ & $\begin{array}{l}\text { Processos de } \\
\text { união }\end{array}$ & $\begin{array}{c}\text { Competência, } \\
\text { capacidade e } \\
\text { poderes do pessoal }\end{array}$ \\
\hline $\begin{array}{l}\text { 16-Oferecer brindes eventuais } \\
\text { para clientes }\end{array}$ & $\begin{array}{l}\text { Orientação para o } \\
\text { Cliente }\end{array}$ & $\begin{array}{l}\text { Estrutura e Sistema } \\
\text { Organizacional }\end{array}$ & $\begin{array}{l}\text { Processos } \\
\text { de união }\end{array}$ & $\begin{array}{l}\text { Ir ao encontro dos } \\
\text { clientes }\end{array}$ \\
\hline
\end{tabular}

Quadro 4 - Resumo das atividades desenvolvidas e relação com a literatura.

Fonte: Elaborado pelos autores.

O mesmo nível de aprimoramento pode ser dado a programas de bonificação a clientes. Estas atividades: gestão eficaz dos recursos humanos com foco no cliente, obtenção de informação no 
ambiente e programas que vão além das expectativas do consumidor parecem necessitar da atenção contínua da alta gerência, na medida em que a integração de todos os processos da empresa pode antecipar as necessidades dos clientes, além de promover um contínuo processo de inovação organizacional representando oportunidades no mercado (Bacon, 2003; Martilla \& James, 1977). As atividades e os atributos pontuais: cardápio, melhores treinamentos com funcionários e relações diretas e diárias com os clientes, a isoavaliação, apontam que deve ser dada importância prioritária, pois são necessidades que devem ser sempre satisfeitas. Apesar de a IPA ser fundamentada de forma intuitiva e possuir uma certa simplicidade na análise (Bacon, 2003), a maioria dos respondentes já havia classificado estes atributos como suas prioridades para constante melhoria.

Há também que se observar que os resultados em relação ao item banco de dados contradizem a pesquisa realizada pela ANR (Santos, 2010), que aponta que $89 \%$ dos restaurantes por quilo realizam pesquisa de satisfação e $75 \%$ mantêm cadastro de sua clientela. As evidências sobre a escassez de recursos no campo da competitividade dessas organizações fazem da gestão uma coordenação dinâmica focada em atividades que não sejam distorcidas e não estão sujeitas à eliminação dos processos organizacionais. Isto parece indicar que há uma marcante orientação para resultados positivos a partir de atividades que priorizem a geração de valor para os clientes por meio da eficiente alocação de recursos.

Destarte, as atividades desenvolvidas por meio dos processos organizacionais, encontradas nas empresas pesquisadas, apontam que existe uma cultura organizacional que possui determinados componentes comportamentais (Narver \& Slater, 1990) que irão orientá-las para o mercado. Esta OPM parece estar relacionada a um conjunto de recursos e fatores internos que influenciam atividades antecedentes (Jaworski \& Kohli, 1993) na geração e na divulgação de informação por toda a organização, capacitando-a para desenvolver respostas à satisfação dos clientes. A capacitação acontece por meio desses mesmos processos organizacionais, a qual permitirá que a organização antecipe as necessidades do mercado (Day, 1994) e crie uma gestão eficiente, positiva e com duradouras relações com clientes (Whiteley, 1991).

Dessa maneira, a partir de atitudes empreendedoras de seus gestores que estimulam processos que apreendem intelectualmente todos os setores das empresas, pode-se articular que elas contêm em si uma capacidade de entendimento e de percepção daquilo que satisfaz ou não seu cliente e, ao mesmo tempo, desenvolvem faculdades que se relacionam com o equilíbrio e com o desempenho das atividades e que se aplicam dinamicamente no dia a dia para gerar valor para todos.

Finalmente, no Quadro 4, pode-se observar que a estratégia de gestão dessas empresas possui características comportamentais que coordenam suas atividades entre várias frentes para geração de 
valor para o cliente (Narver \& Slater, 1990), motivando dinâmicas interdepartamentais a partir da orientação empreendedora da alta administração (Jaworski \& Kohli, 1993). Todos esses processos gerados no interior da organização, as informações adquiridas no ambiente em que atuam, a integração desses conhecimentos desenvolvidos e transformados em atividades e em atributos (Day, 1994) permitem criar relações duradouras por meio de um alinhamento estratégico com seus clientes (Whiteley, 1991).

\section{CONSIDERAÇÕES FINAIS}

Este estudo pretendeu averiguar a relação entre OPM e PMEs em uma amostra de restaurantes por quilo na cidade de São Paulo. O objetivo foi descobrir quais atividades de marketing restaurantes por quilo com mais de 10 anos de existência na cidade de São Paulo desenvolvem a fim de promover um desempenho superior no ambiente em que atuam.

As atividades estratégicas desenvolvidas parecem contribuir na promoção de um desempenho superior em relação aos seus concorrentes. Elas são elaboradas no bojo de processos organizacionais a partir dos seus escassos recursos. Tal resultado mostra total alinhamento com a literatura analisada, principalmente nos aspectos dos componentes comportamentais (Narver \& Slater, 1990) e dos antecedentes da OPM (Jaworski \& Kohli, 1993). Pode-se observar que há uma dinâmica constante e, na maioria das vezes, informal para que colaboradores internos busquem inspiração e modelos de comportamento junto aos clientes com foco na geração de valor para eles. Este comportamento, integrado à gestão, recebe e processa constantemente informações do ambiente em que atua. Dessa maneira, os atributos percebidos e identificados como desejos e preferência dos comensais buscam ser desenvolvidos dentro das possibilidades da viabilidade de cada restaurante. Esta dinâmica está de acordo com os fatores da orientação para o cliente, de Whiteley (1991), mostrando adequação com esta parte da literatura analisada.

Como havia previsto Day (1994), em suas categorias das capacidades, uma dinâmica destas, que orientam tais empresas para o mercado, é assim desenvolvida apoiando-se na capacidade de absorver informação do ambiente e de disseminá-la e de convertê-la em processos, assim como de integrá-los, a fim de obter um desempenho superior. As atividades desenvolvidas na promoção de um desempenho superior pelos restaurantes por quilo pesquisados puderam correlacionar a OPM a partir da IPA. Neste contexto, o grau de OPM parece refletir o grau em que os recursos disponíveis dessas PMEs são alocados em busca de melhor desempenho.

Revista de Administração e Inovação, São Paulo, v. 9, n. 1, p.188-210, jan./mar. 2012. 
A alocação de recursos gera a atenuação de riscos no ambiente de atuação, o que sugere ser a OPM uma estratégia que tem efeito direto no desempenho dessas empresas, mas se mostrou aquém das expectativas dos gestores, considerando-se a lacuna em relação à concorrência. Tais aspectos necessitam de maior investigação, uma vez que o modelo aplicado da IPA foi baseado em atributos de gestão, e a importância absoluta dada por meio do próprio modelo de negócio apresentou um elevado grau de homogeneidade, mas não discriminativo. Tal resultado sugere uma incidência dessas atividades no mesmo quadrante, gerando provável distorção investigativa.

Estabelece-se, dessa forma, que esta IPA fica condicionada ao melhor entendimento que os gestores possuem acerca dos atributos e das atividades desenvolvidas e, para dirimir as questões da validade preditiva, sugere-se desenvolver uma nova pesquisa a partir da outra ponta do serviço prestado, ou seja, os clientes.

A limitação da amostra aplicada nesta pesquisa pode apresentar limitações para uma eficiente validade prática e sugere-se considerar uma variedade maior dos atributos e das atividades, além da validação da pesquisa sob a perspectiva do cliente. Embora o modelo IPA tenha sido capaz de indicar a melhor distribuição dos recursos das empresas a partir da demanda de seus clientes, espera-se que futuras pesquisas com foco nas duas pontas do espectro do mercado, quem presta e quem recebe o serviço, possam contribuir para um melhor entendimento do problema e da criação de valor para todos.

Finalmente, a partir de uma OPM, as informações adquiridas pelas PMEs parecem indicar a necessidade de priorizar certas atividades que promovam adequadamente as oportunidades do mercado descobertas, tornando-as exequíveis a baixo custo. Por outro lado, deve-se ter consciência de que se corre o risco de ficar vulnerável frente aos concorrentes devido a uma ênfase exagerada na satisfação do cliente sem a contrapartida eficiente dos recursos.

\section{REFERÊNCIAS}

Ainin, S., \& Hisham, N. H. (2008). Applying importance- performance analysis to information systems: an exploratory case study. Journal of Information, Information Technology, and Organizations, 3, 95-103.

Appiah-Adu, K. (1998). Marketing activities and business performance: evidence from foreign and domestic manufacturing firms in a liberalized developing economy. Marketing Intelligence \& Planning, 16(7), 436-442.

Associação Brasileira das Indústrias da Alimentação. (2011). O mercado food service no Brasil. São Paulo: Autor.

Bacon, D. R. (2003). A comparison of approaches to importance-performance analysis. International

Revista de Administração e Inovação, São Paulo, v. 9, n. 1, p.188-210, jan./mar. 2012. 
Journal of Market Research, 45(1), 55-71.

Baker, T. L., Simpson P. M., \& Siguaw, J. A. (1999). The impact of suppliers' perceptions of reseller market orientation on key relationship constructs. Journal of the Academy of Marketing Science, 27(1), 50-57.

Baker, W. E., \& Sinkula, J. M. (2009). The complementary effects of market orientation and entrepreneurial orientation on profitability in small businesses. Journal of Small Business Management, 47(4), 443-464.

Blankson, C., \& Cheng, J. M-S. (2005). Have small businesses adopted the market orientation concept? The case of small businesses in Michigan. The Journal of Business \& Industrial Marketing, 20(6), 317-331.

Cannon, J. P., \& Homburg, C. (2001). Buyer supplier relationships and customer firm costs. Journal of Marketing, 65(1), 29-43.

Chen, I-S., \& Chen, J-K. (2010). Disparities between services demanded and Services received in Taiwanese restaurants. Global Journal of Business Research, 4(1), 59-70.

Day, G. S. (1994). The capabilities of market-driven organizations. Journal of Marketing, 58(4), 3752.

Deng, W. (2007). Using a revised importance-performance analysis approach: the case of Taiwanese hot springs tourism. Tourism Management, 28(5), 1274-1284.

Deshpandé, R., Farley, J. U., \& Webster, F. E., Jr. (1993). Corporate culture, customer orientation, and innovativeness in Japanese firms: a quadrad analysis. Journal of Marketing, 57(1), 23-27.

Donato, D. R. (2009). Restaurante por quilo: uma área a ser abordada. São Paulo: Metha.

Duchessi, P., \& Chengalur-Smith, I. (2008). Enhancing business performance: via vendor managed inventory applications. Communications of the ACM, 51(12), 121-127.

Graf, L. A., Hemmasi, M., \& Nielsen, W. (1992). Importance satisfaction analysis: a diagnostic tool for organizational change. Leadership \& Organization Development Journal, 13(6), 8-12.

Hawes, J. M. (1985). Using importance-performance analysis to develop health care marketing strategies. Journal Health Care Marketing, 5(4), 19-25.

Hourd, P. C., \& Williams, D. J. (2008). Results from an exploratory study to identify the factors that contribute to success for UK medical device small- and medium-sized enterprises. Proceedings of the Institution of Mechanical Engineers - Part H: Journal of Engineering in Medicine, 222(5), 717 735.

Ibelli, R. C. (2006, julho 31). Pequenos fogem da falência com parcerias. Recuperado em 13 de agosto, 2011, de http://enebecontabil.com.br/escritorio/informativo_texto.asp?sequencia=392.

Jaworski, B. J., \& Kohli, A. K. (1993). Market orientation: antecedents and consequences. Journal of

Revista de Administração e Inovação, São Paulo, v. 9, n. 1, p.188-210, jan./mar. 2012. 
Marketing, 57(3), 53-70.

Kaplan R. S., \& Norton D. P. (1996). Using the balanced scorecard as strategic management system. Harvard Business Review, 74(1), 75-85.

Lakatos, E. M., \& Marconi, M. A. (1985). Fundamentos de metodologia científica. São Paulo: Atlas.

Li, Y., Zhao, Y.,Tan, J., \& Liu, Y. (2008). Moderating effects of entrepreneurial orientation on market orientation-performance linkage: evidence from Chinese small firms. Journal of Small Business Management, 46(1), 113- 314.

Lin, S. P., Chan, Y. H., \& Tsai, M. C. A. (2009). Transformation function corresponding to IPA and gap analysis. Total Quality Management, 20(8), 829-846.

Maricato, P. (2005). Marketing para bares e restaurantes. Rio de Janeiro: Senac Nacional.

Martila, J. A., \& James, J. C. (1977). Importance-performance analysis. Journal of Marketing, 1(41), 77-79.

Martin, B. A., \& Martin, J. H. (2005). Building a market-oriented organizational environment: an implementation framework for small organizations. Mid-American Journal of Business, 20(2), 4558.

Moretti, S. L. A., Moyses, J. E., Filho, \& Pereira, R. D. A. (2010). Inovação no desenvolvimento de produto para o mercado de sobremesas prontas: o caso da Laffriolée. Revista de Administração e Inovação, 7(1), 21-35.

Moyses, J. E., Filho., \& Pereira, R. D. A. (2008). Parceria colaborativa no desenvolvimento de produto em pequenas empresas: um estudo de caso. Anais do Encontro de Estudos sobre Empreendedorismo e Gestão de Pequenas Empresas, São Paulo, SP, Brasil, 5.

Narver, J. C., \& Slater, S. F. (1990). The effect of a market orientation on business profitability. Journal of Marketing, 54(4), 20-35.

Parasuraman, A., Zeithaml, V. A., \& Berry, L. L. (1985). A conceptual model of service quality and its implications for future research. Journal of Marketing, 49(4), 41-50.

Pelham, A. M. (2000). Market orientation and other potential influences on performance in small and medium sized firms. Journal of Small Business Management, 38(1), 48-67.

Pelham, A. M., \& Wilson, D. T. (1996). A longitudinal study of the impact of market structure, firm structure, strategy, and market orientation culture on dimensions of small-firm performance. Journal of the Academy of Marketing Science, 24(1), 27-43.

Pereira, D., Lucas, R. B., \& Minciotti, S. A. (2008). Mortalidade das micro e pequenas empresas e a aplicação das técnicas de marketing. Revista de Administração da FEAD, 5, 20-37.

Perin, M. G., \& Sampaio, C. H. (2004). Orientação para o mercado, porte empresarial e performance. Revista de Administração de Empresas, 4(3), 76-88. 
Rojas-Mendez, J. I., Kara, A., \& Spillan, J. E. (2006). Market orientation in the Chilean small business context: an empirical study. Journal of Global Marketing, 19(3-4), 93-132.

Ruerkt, R. W. (1992). Developing a market orientation: an organizational strategy perspective. International Journal of Research in Marketing, 9(3), 225-245.

Sampaio, C. H., Perin, M. G., \& Ferreira, G. C. (2008). A relação entre sucesso de novos produtos, orientação para o mercado e performance empresarial. Produto \& Produção, 9(3), 85-94.

Santos, R. F. (2010). Um retrato dos restaurantes: pesquisa sobre o setor de alimentação fora do lar mostra como estão faturamento, empregabilidade, gestão e principais desafios dos estabelecimentos. Recuperado em 30 de julho, 2010 de http://revistapegn.globo.com/Revista/Common/0,,EMI130192-17180,00-

UM+RETRATO+DOS+RESTAURANTES.html.

Shapiro, B. P. (1988). What the hell is 'market orientation'? Harvard Business Review, 66(6), 119125.

Siguaw, J. A., Simpson, P. M., \& Baker T. L. (1998). Effects of supplier market orientation on distributor market orientation and the channel relationship: the distributor perspective. Journal of Marketing, 62(3), 99-111.

Souza, A. C. R., \& Mello, S. C. B. (2007). Uma avaliação das dimensões da escala de orientação para o mercado de George Day. Revista de Negócios, 12(2), 69-84.

Tavares, B., Ferreira, M. A. M., \& Lima, A. A. T. F. C. (2009). Identificação das práticas de gestão das micro e pequenas empresas: construindo uma escala de mensuração. Revista de Negócios, 14(4), $11-27$.

Teles, M. F. B. (2007). Orientação para o mercado e a projecção do desempenho empresarial - casos de aplicação em PME. Dissertação de Mestrado, Universidade do Porto, Porto, PT.

Vergara, S. C. (2006). Projetos e relatórios de pesquisa em administração (7a ed.). São Paulo: Atlas.

Verhees, F. J. H. M., \& Meulenberg, M. T. G. (2004). Market orientation, innovativeness, product innovation, and performance in small firms. Journal of Small Business Management, 42(2), p. 134154, 2004.

Whiteley, R. (1991). A empresa voltada totalmente para o cliente. Rio de Janeiro: Campus.

Wiklund, J., Patzelt, H., \& Shepherd, D. A. (2009). Building an integrative model of small business growth. Small Business Economics, 32(4), 351-374.

Yang, J. (2008). Unravelling the link between knowledge integration and new product timeliness. Technology Analysis \& Strategic Management, 20(2), 231-243.

Yin, R. K. (2005). Estudo de caso: planejamento e métodos (3a ed.). Porto Alegre: Bookman. 
Zhang, Z. (2000). Developing a model of quality management methods and evaluating their effects on business performance. Total Quality Management, 11(1), 129- 137.

\title{
MANAGEMENT AND CUSTOMER ORIENTATION: A STUDY IN RESTAURANTS PER KILOGRAM USING THE MODEL OF IMPORTANCE AND PERFORMANCE ANALYSIS
} (IPA)

\begin{abstract}
Studies on management of small and medium enterprises (SMEs) from the perspective of market orientation (OPM) have been rare in Brazil. This article, which applied the model analysis of importance (IPA), aims to determine which marketing activities, designed under the principles of OPM, are adopted by a sample of restaurants per kilogram (SMEs) with over 10 years of existence in the city of São Paulo. The results indicate that there is a momentum generated by the internal staff to identify customer preferences and desires and transform them into services.
\end{abstract}

Keywords: Market orientation (OPM); Small and medium enterprises (SMEs); Model importance and performance analysis (IPA).

Data do recebimento do artigo: 21/04/2011

Data do aceite de publicação: 28/08/2011 